\title{
Research into the Construction of Communication Courses at Application-Oriented Colleges and Universities under Informatization
}

\author{
Nan Li \\ Xi'An JiaoTong University City College, 710018
}

\begin{abstract}
Keywords: Informatization; Application-oriented colleges and universities; Construction of communication courses
\end{abstract}

\begin{abstract}
The communication course is one of the fundamental courses in science and engineering. The current economic and social development is inextricably linked with the advancement of communications technology. In a sense, informatization is based on the premise and core content of the advancement of communications technology. Currently, the construction of communication courses at application-oriented colleges and universities is relatively backward with respect to the overall requirements for personnel training goals. How to do a good job in the construction of communication courses in applied colleges and universities is a real problem that needs urgent solution.
\end{abstract}

Application-oriented colleges and universities are an important part of China's higher education system. Application-oriented colleges and universities shoulder the historic mission of cultivating and bringing up applied talents for China's economic and social development and socialist modernization. Education is a process and its essence is to promote people's all-round development. The education and teaching process of application-oriented colleges and universities can best reflect this essence of education. Based on their own characteristics, application-oriented colleges and universities should boldly innovate in education, constantly update education concepts and focus on construction the application-oriented talent cultivation model suitable for the social development, training and emitting application-oriented compound and outward-oriented talents for the society.

After years of development in China's higher education, fruitful results and considerable progress have been achieved in many aspects, but in some places there are still unsatisfactory places, such as the problem of lagging-behind construction of course systems. The existence of this issue has its historical and practical reasons. However, if we do not seriously face and accelerate the solution to this problem from the overall perspective, our higher education will stop and seriously hinder the orderly development of the talent training program. At present, China's higher education has entered the popularization stage. The government has formulated plans for the cultivation of higher-level talents that are close to actual needs. The Outline of the National Medium- and Long-Term Education Reform and Development Plan (2010-2020) clearly states that it is necessary to expand the training scale of applied, compound, and skilled talents. As far as the communication major is concerned, we should focus on training application-oriented talents and R\&D talents for communication engineering that are oriented towards the market and production.

\section{Requirements and Challenges of Informatization for Communication Course Construction}

Nowadays, the rapid development of the information technology has brought convenience to us, which can be clearly felt in all walks of life. From a certain perspective, informationization is based on the development of communication technology and its core content. Therefore, there is an inseparable relationship between information technology and the advancement of communications technology. They are mutual related to each other to form a mutually promoting process. The mobile Internet industry based on mobile communications and computer technology has become an important pillar of China's economic development. With the ever-increasing size of related industries, the demand for application-oriented communication talents in the society is increasing year by year, and the requirements for the comprehensive ability and accomplishment of communication professionals have also been updated. The application-oriented communication professional curriculum should be set in line with the trend of the times and must meet the needs of 
the current communications industry. From the point of view of the development trend of communication technology, it is closely integrated with computer technology. The current software-defined networks, the fifth-generation mobile communication network, and the Internet of Things can all be classified as extensions of the communication major. The demand for talents in the communications industry has also shifted from the traditional equipment-based core to service-based. This requires our communications professionals not only to master basic professional knowledge, but also to have the skills of communication network management, operations, and development. However, it is obvious that, for the current curriculum setting for communication majors at application-oriented colleges and universities, it is far from being able to achieve this goal of talent cultivation.

Curriculum construction has a very important position in education and teaching. It is one of the prerequisites for the smooth development of university education and teaching. It is the basic work for professional development and the growth of disciplines. It is the most direct, essential and basic factor in improving the quality of personnel training. The development of the times and the advancement of science and technology have put forward new and updated requirements for our traditional talent training model. Therefore, accelerating the construction of communication courses for applied undergraduate colleges is in full swing. We must correct traditional teaching concepts, restructure course structures and teaching contents, reform teaching methods, and explore innovative curriculum evaluation mechanisms to promote the reform and innovation of communication courses.

In order to implement the idea of education and teaching, the construction of the course system should be depended on. In the new historical period and under the background of education and teaching reform, we must grasp the ties of curriculum construction. Through the scientific planning, design, and implementation of curriculum content, education ideas can be materialized into education and teaching achievements. Communication courses are an important part of the curriculum system of applied undergraduate colleges. Under the conditions of informatization, the reform and construction of communication courses are of great significance in guiding and social values.

\section{Main Problems Existing in Communication Courses in Current Application-oriented Universities}

Different colleges and universities vary in terms of the strength of teachers, comprehensive strength, and quality of students. Therefore, the differences in the setting of communication courses in various application-oriented colleges and universities are also large. However, the author believes that, in general, the following problems commonly exist in teaching communication course:

The Educational Ideas Are Outdated. In recent years, China's higher education has been developing rapidly. However, many college and university teachers still do not keep up with the pace of development of the times in their ideology. They are old-fashioned, and they are self-styled, making the promotion of advanced educational concepts stagnant. Under the background of quality education, we should take students as the main body in education and teaching, and try to mobilize the enthusiasm and initiative of students' learning. As far as possible, the methods of heuristics and discussion should be adopted in teaching so that students can deepen their understanding of relevant concepts and theoretical knowledge through their own thinking. In terms of teaching content, on the one hand, we must pay attention to grasping the overall progress of the curriculum according to the outline requirements. On the other hand, we must try to incorporate as much of the communication-related cutting-edge knowledge into the curriculum as possible, such as some of the latest communication results, to make students feel as much as possible that communication knowledge not only stays on paper, but is real, affecting our lives every moment.

The Course Setting is Unreasonable. As mentioned before, communication technology and computer technology are inextricably linked in the current development of science and technology. It is difficult to separate the two and they basically rely on each other. However, current communication courses mainly include courses such as circuit analysis, analog electronic circuits, 
digital electronics, and high-frequency electronic circuits. However, there are only a few C language programming and microcomputer principles in the interface courses with computers, and some are elective courses. At the same time, there are not many practical training courses for students in the communication course, which is mainly based on theoretical knowledge. Practical teaching will not only help students understand and digest theoretical professional knowledge, improve students' creativity and creativity, but also help cultivate students' awareness of group collaboration and collaboration.

The Content of Course Materials Is Backward and Rigid. Of course, we are not here to deny the importance of basic principles and basic knowledge. However, the content of the teaching materials has changed little in the past few years. The examples and after-school exercises in the teaching materials are not closely related to practical life applications, and it is difficult to stimulate students' interest in learning. Each application-oriented college and university should organize relevant teachers to proceed from the characteristics of school running and the actual conditions of running a school to compile teaching materials that meet the teaching requirements and professional construction requirements of the school and have distinctive characteristics of the times.

Education and Teaching Methods Are Relatively Backward. Whenever this issue is mentioned, as a teacher who has long been engaged in communication professional courses, I have an unspeakable feeling. The convenience brought to us by information has gone deep into the corners of life. As a communication course closely related to informatization, traditional teaching methods and means are used at many colleges and universities. This is related to the school's capital investment on one hand. On the other hand, it is related to our course system construction ideas. We should vigorously promote the informatization of communication courses, make full use of class time, and improve classroom efficiency.

Students' Practical Ability Is Poor. The communication course should have been a very practical course, but the current method of knowledge transmission in this course is mainly based on theoretical indoctrination. With regard to how to improve students' practical abilities and practical abilities, the academic community has made explorations and bold attempts in both theory and practice in recent years and has achieved notable achievements, such as the development of school-enterprise cooperation. But overall, there is still a big gap between our colleges and universities in terms of training the talents' hands-on ability, practical ability and innovation ability. In the current transformation of education, how can we achieve turning overtaking and effectively improve students' comprehensive ability is an urgent issue of the times.

\section{Research on the Ways of Constructing Communication Courses at Application-oriented Colleges and Universities under Informatization}

Nowadays, with the rapid development of the information technology, all colleges and universities should start from their own characteristics to formulate a set of scientific and feasible talent training scheme according to the changing trending of requirements for talents in this industry, clarify the talent training objective and firmly grasp curriculum construction to focus on improving the level and quality of talent training.

Clarify the Talent Training Thoughts. The communications industry has developed rapidly. Therefore, our talent training ideas cannot be fixed, but should be regularly updated. First of all, we should do a good job of research, organize related professional teachers to discuss the project, and at the same time we must appoint experts to the enterprise, conduct in-depth investigations and exchanges with employers, understand the problems found in the process of employing companies, and report the information collected to the teaching management department in a timely manner. On the other hand, we should also listen carefully to students' opinions on this course, organize discussions and exchanges, and allow students to make bold statements. Based on this, we can further refine our work ideas.

Pay Attention to Training Students' Practical Application Ability. In the construction of communication courses, we must closely follow this point of engineering application. We must focus on improving students' hands-on ability. In teaching, every effort should be made to provide 
students with hands-on opportunities, both in experimental design and in course design. As far as conditions permit, the teaching of some knowledge points can be conducted in the laboratory, allowing students to learn while practicing. The construction of a practical teaching system is a systematic project guided by scientific principles. First of all, we should pay attention to the principle of integrity. We must pay attention to the integrity of theoretical teaching and practical teaching, highlight the interrelationship between the two, and infiltrate each other. We must distinguish between them and treat them separately. Secondly, the development of practical teaching should be carried out in an orderly manner. Generally speaking, it should be after theoretical teaching so as to ensure the realization of teaching quality and teaching objectives. Finally, it is necessary to grasp the principle of efficiency, that is, to avoid repetitive experiments, to save resources and funds, and to avoid occupying students' valuable practice time. The experimental teaching is an organic part of the curriculum system of application-oriented undergraduate colleges and universities. Although it has a certain degree of independence, more attention should be paid to its overall characteristics in the design and implementation.

Focus on Cultivating High-quality Teachers. The level of teaching staff is often the decisive factor in the quality of teaching. Due to the level of regional economic development in our country and the inequality of schools' investment in specific professions, different majors at different colleges differ greatly in the level of development, so is the construction of the teaching team. At the school level, it is necessary to strengthen the long-term construction of the teaching staff and give full attention to this issue and make constant efforts. We must adhere to the principles of introduction and delivery. On the one hand, we must strengthen the introduction of talents and recruit professional and highly-qualified professionals who are in urgent need of professionalism. On the other hand, teachers should try their best to provide opportunities for learning and communication so that teachers can flow.

Further Strengthen the Awareness of Cooperation. By strengthening the school-enterprise cooperation, excellent engineering and technical personnel in the company can be invited to teach in class. While supplementing teachers, students can also broaden their horizons and understand the application of professional knowledge in the enterprise, their needs and development. At the same time, the cooperation between universities can move forward to a deeper and broader level, fully absorbing and learning from each other and improving together.

This mode of school-enterprise cooperation has developed rapidly over the years. Judging from its practical effects, it has greatly contributed to the improvement of students' practical ability and collaborative spirit. We must pay attention to all-round and multi-angle development of school-enterprise activities. Schools can invest together with companies to establish practical training bases. Training bases include off-campus training bases and on-campus training bases. Off-campus training bases are mainly based on enterprises and may include communication equipment manufacturers, sellers, and operators. Through the establishment of an off-campus training base, students can be placed on the eve of graduation to work internships, and personally feel the company's organizational model and operating model. The school can follow up the training process and find problems and hidden dangers in the training and education of students. These problems and dangers can be collected and fed back, thus the deficiencies can be corrected in the course construction in practice.

Optimize the Communication Course Assessment Mechanism. The scientific assessment mechanism has a very positive guiding role for the construction of the curriculum. We can no longer only emphasize on exam scores, which is taken as the basis for the evaluation of communication courses in traditional. Instead, we should establish an assessment system that is comprehensive, efficient, and balanced with both theoretical and practical levels. In this system, hands-on ability, practical ability and other aspects should be given full attention to. The methods of assessment should also be diversified, and should not be limited to the form of written examinations, defenses, submission of reports, etc. They can be fully incorporated into the assessment system. Only in this way can the construction of the curriculum system form a complete chain. 


\section{Conclusion}

Curriculum construction is the foundation and core content of the training of communication professionals. We must take the main course of communication course construction as a starting point and continuously modify the construction of the curriculum system from both theoretical and practical aspects. This will not only emphasize the study of theoretical knowledge, but also emphasize the cultivation of practical abilities and safeguard the overall quality of students.

\section{References}

[1] Zhao Fayong, Research into Teaching Communication Theory Course [J]. China Electric Power Education, 2008,(120):71-73.

[2] Zhou Guping, Xu Liqing, On the Objective of Training Application-oriented Talents at Newly-established Colleges and Universities [J]. Journal of Zhejiang Wanli University,2005 (5).

[3] Si Shumei, Research into the Application-oriented Undergraduate Education's Practical Teaching System [D]. Northeast Normal University, 2006.

[4] Yuan Xiawei, Li Na,On Constructing a New System of Practice Teaching in College of Engineering [J]. Science and Education, 2007 (5) : 65-67.

[4] Yang Shuchen. Research and Practice of " $3+1$ " Teaching Mode for Communication Engineering Major [J]. Journal of Jilin Institute of Engineering and Technology Teachers, 2011 (2) :7-9.

[5] Guo Yecai, Huang Yourui, Zhu Zongxi. The 2+2 Course System Construction and Characteristics of Communication Engineering [J]. China Science and Technology Information, 2006 (1):84.

[6] Pan Maoyuan, Zhou Qunying, Application-Oriented Undergraduate Curriculum Construction from the Perspective of University Classification [J]. Chinese University Teaching, 2009 (3) :4-7

[7] $\mathrm{Hu}$ Xiaojuan, Questions and Reflections on Application-oriented College Curriculum in China [J]. Value Engineering, 2004（5）:228-229.

[8] Zhu Yuexiu, Modern Communication Technology [M]. Beijing: Electronic Industry Press, 2010.

[9] Chu Lili, Thoughts on the Reform of Curriculum System of Communication Engineering under the New Situation [J]. China Electric Power Education, 2010（33）:125-126. 